\title{
Optimalisasi Manajemen Masjid Sebagai Pusat Kegiatan Pemberdayaan Masyarakat Dusun Daleman
}

\author{
Chusnul Azhar', Krisdiyanto ${ }^{2}$ \\ ${ }^{1}$ Pragram Studi Teknik Mesin, Fakultas Teknik, Universitas Muhammadiyah Yogyakarta, Jl Brawijaya, Kasihan, Bantul 55183 \\ Email: chusnul.azhar@umy.ac.id \\ DOI: $10.18196 / \mathrm{ppm} \cdot 32.201$
}

\begin{abstract}
Abstrak
Masjid adalah bangunan yang sengaja didirikan umat muslim untuk melaksanakan salat berjamaah dan berbagai kegiatan lain yang terkait dengan kemaslahatan umat muslim hingga menjadi simbol kemajuan umat Islam sejak dahulu. Akan tetapi, bila mencermati fungsi masjid saat ini, fungsi yang kedua ini cenderung hilang di banyak masjid lantaran masjid hanya dipahami sebagai tempat shalat lima waktu. Hal itu pun kalau masih berlangsung karena yang terjadi juga banyak masjid yang sepi dalam pelaksanaan salat wajib lima waktu. Keadaan tersebut juga terjadi di beberapa masjid yang berada di wilayah Dusun Daleman. Di sinilah urgensi program pengabdian kepada masyarakat dengan berbagai kegiatan di antaranya adalah sosialisasi dan penyuluhan tentang fungsi masjid, restrukturisasi takmir masjid, pelatihan manajemen pengelolaan kegiatan masjid, dan pengadaan perlengkapan masjid. Rangkaian kegiatan tersebut bertujuan untuk optimalisasi manajemen masjid sebagai pusat kegiatan pemberdayaan masyarakat. Program ini dapat meningkatkan kesadaran warga muslim Dusun Daleman untuk mengembalikan fungsi masjid di wilayah Dusun Daleman, seperti masjid-masjid lain pada umumnya sebagai pusat kegiatan pemberdayaan masyarakat di Dusun Daleman, Gilangharjo, Pandak, Bantul, Daerah Istimewa Yogyakarta.
\end{abstract}

Kata kunci: Manajemen, Masjid, Pemberdayaan, Masyarakat.

\section{Pendahuluan}

Gilangharjo adalah salah satu desa di Kecamatan Pandak, Bantul, Daerah Istimewa Yogyakarta, Indonesia. Desa ini memiliki luas \pm 726 hektare yang terdiri atas 15 dusun. Kelima belas dusun tersebut di antaranya adalah Dusun Daleman yang menjadi mitra program pengabdian pada masyarakat ini. Jumlah penduduk Desa Gilangharjo sebanyak 17.025 jiwa yang terdiri atas 5.500 kepala keluarga. Desa Gilangharjo sedang mempersiapkan diri menjadi desa wisata karena memiliki beraneka potensi pariwisata yang dapat disandingkan dengan desa wisata lainnya. Potensi pariwisata tersebut adalah kuliner, industri rumah tangga, kerajinan, situs sejarah, seni, budaya, dan pemandangan alam pedesaan yang menarik. Desa Gilangharjo juga dikenal karena beragamnya karya seni yang dihasilkan, seperti seni lukis, seni topeng, seni batik, seni tari, seni patung, seni karawitan, dan seni musik.

Dusun Daleman adalah salah satu dari lima belas dusun di Desa Gilangharjo yang secara geografis terletak di bagian ujung utara berdekatan dengan pusat Kota Bantul. Data dari kantor kelurahan Desa Gilangharjo memberikan informasi bahwa komposisi warga Dusun Daleman pada ranah keyakinan memang sangat beragam. Komposisi warga tidak seluruhnya beragama Islam. Berdasarkan data, warga beragama Islam sebanyak $60 \%$ dan pemeluk Nasrani $40 \%$. Walaupun demikian, Dusun Daleman sangat terkenal dengan kekompakan antarwarga walaupun berbeda keyakinan. Hal ini terbukti belum pernah terjadi permasalahan antarpemeluk agama yang berbeda.

Dusun Daleman dilengkapi dengan beberapa fasilitas umum, di antaranya terdapat 2 masjid, 1 mushalla, 1 gereja Protestan, 1 PAUD dan TK ABA, serta 1 SD Negeri. Walaupun berpenduduk mayoritas muslim, tingkat kesadaran beragamanya tergolong rendah. Ini terlihat 
dari keadaan masjid sangat tidak terurus, baik dari segi kepengurusan takmir, kegiatan peribadatan, kegiatan kajian, fasilitas, kerapian, dan kebersihan yang terabaikan.

Oleh karena itu, program pengabdian pada masyarakat ini dilakukan dalam rangka optimalisasi manajemen masjid sebagai pusat kegiatan pemberdayaan masyarakat di Dusun Daleman. Program ini bertujuan untuk dapat mengembalikan fungsi masjid di wilayah Dusun Daleman dalam wujud pengembangan kapabilitas intelektual umat, kegiatan sosial kemasyarakatan, peningkatan perekonomian umat, dan ruang diskusi untuk mencari solusi permasalahan umat terkini.

\section{Metode Pelaksanaan}

1. Tahapan sosialisasi diselenggarakan dalam wujud pengajian akbar dengan menghadirkan tokoh Islam Bantul sebagai pembicara dengan tema Urgensi Optimalisasi Manajemen Masjid. Acara ini diselenggarakan dalam rangka memberikan penyuluhan kepada seluruh warga muslim Dusun Daleman dengan tujuan menyamakan persepsi tentang pentingnya masjid sebagai pusat kegiatan keislaman dan pemberdayaan masyarakat.

2. Tahapan kedua adalah pembentukan pengurus takmir masjid. Pada tahapan ini dilakukan pembentukan ulang pengurus takmir masjid yang sudah pernah tersusun serta melibatkan tokoh agama dan masyarakat secara bersamaan untuk keberlangsungan rancangan program kegiatan yang berkelanjutan.

3. Tahapan ketiga adalah menyelenggarakan pelatihan manajemen kegiatan masjid. Pada tahapan ini dilakukan pelatihan manajemen masjid, mulai dari pengeloaan unit TPA sesuai standar manajemen pengelolaan unit TPA Balai Litbang LPTQ Nasional Team Tadarus AMM Yogyakarta, kegiatan kajian, kegiatan pemberdayaan masyarakat, pengelolaan keungan, dan kebersihan.

4. Tahapan yang keempat adalah pengadaan fasilitas masjid. Pada tahapan ini dilakukan pengadaan kelengkapan masjid sebagai sarana berbagai kegiatan rutin, di antaranya papan bagan pengurus takmir masjid, papan pengumuman, papan tulis, alat tulis kantor, perpustakaan masjid, mushaf Alquran, rak Alquran, rak buku, peralatan salat, lemari peralatan salat, dan alat kebersihan.

\section{Hasil dan Pembahasan}

\section{Sosialisasi}

Sosialisasi dilakukan kepada seluruh stakeholder Dusun Daleman yang meliputi berbagai pihak, di antaranya kepala dukuh, ketua RT, tokoh agama, dan tokoh masyarakat dengan tujuan untuk menyamakan persepsi tentang fungsi masjid bagi masyarakat. Kegiatan ini merupakan tahap awal yang ditempuh agar tujuan pendirian masjid dapat pahami dengan baik oleh semua pihak. Tahapan sosialisasi ini dilaksanakan dalam bentuk kegiatan tabligh akbar dengan menghadirkan pembicara Drs. H. Saebani, M.Pd., M.A. (Ketua MUI Kabupaten Bantul) dengan tema "Masjid di Zaman Nabi". Kegiatan ini diselenggarakan sebagai wahana sosialisasi dan penyuluhan dengan mengundang tokoh agama, tokoh masyarakat, dan seluruh warga Dusun Daleman untuk menjalin kerja sama yang baik antar-stakeholder di Dusun Daleman dalam pengelolaan masjid. 


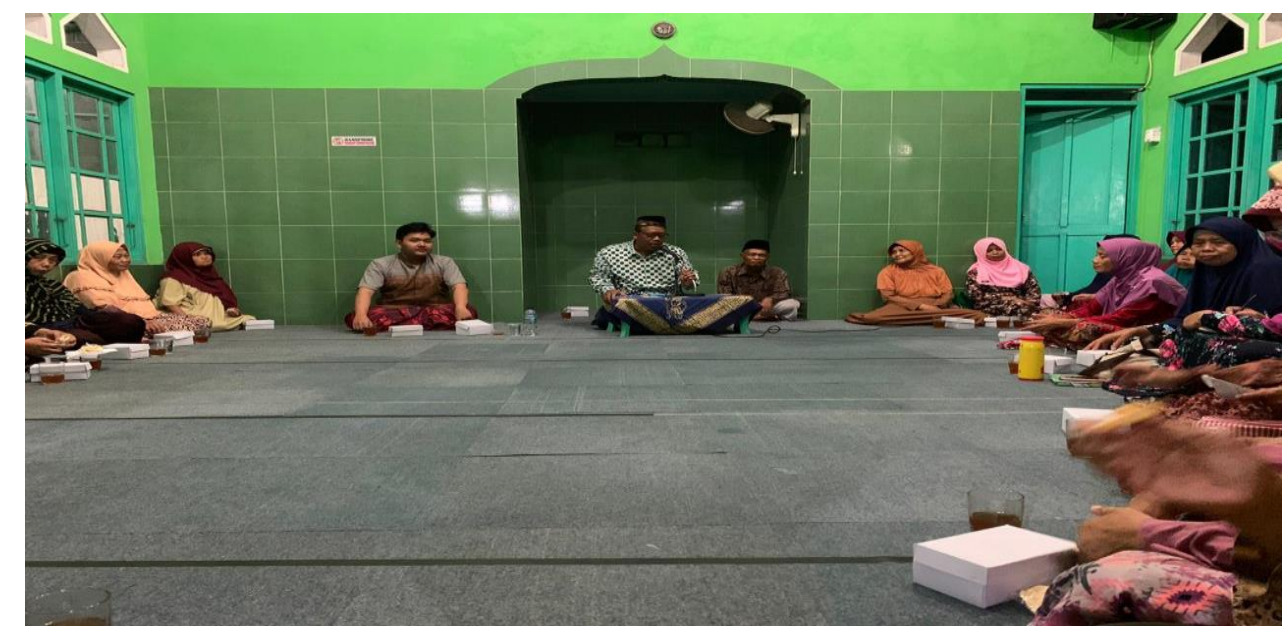

Gambar 1. Sosialisasi melalui Tabligh Akbar

Pada tahapan ini dilakukan sosialisasi kepada seluruh warga Dusun Daleman untuk memberikan pemahaman dan penyatuan persepsi masyarakat tentang urgensi optimalisasi masjid sebagai pusat pemberdayaan masyarakat serta memberikan penekanan tentang keutamaan memakmurkan masjid dengan berbagai kegiatan keagamaan dan kemasyarakatan sebagaimana masjid-masjid lain yang lebih maju dengan penyelenggaraan berbagai program kegiatan.

\section{Pembentukan Pengurus Takmir Masjid}

Setelah berhasil mengumpulkan tokoh agama, tokoh masyarakat, dan seluruh warga Dusun Daleman dalam sosialisasi dan penyuluhan, tahapan selanjutnya adalah melakukan pendataan pengurus takmir masjid yang pernah dibentuk untuk restrukturisasi dan dikawal untuk menyusun program-program kegiatan baru agar kegiatan masjid makin beragam dan bermanfaat bagi masyarakat setempat.

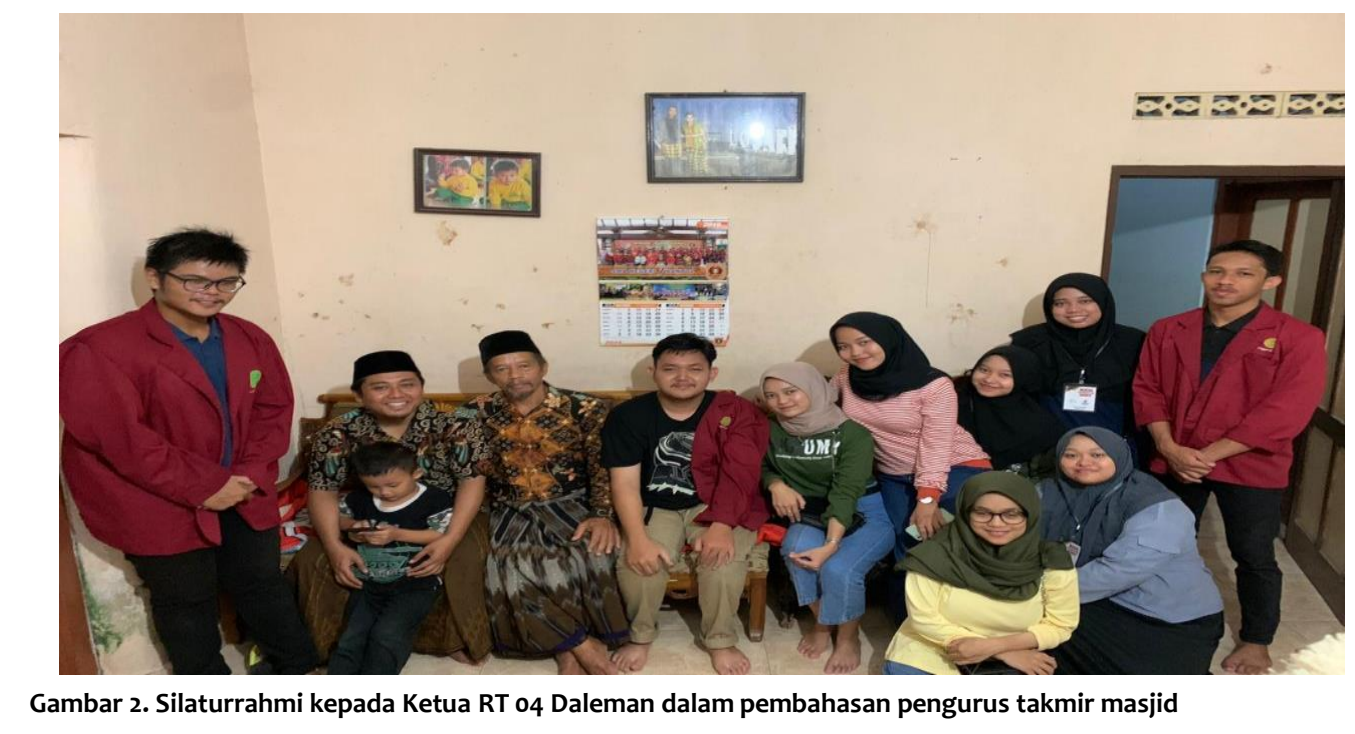

Pada tahapan ini disusun ulang pengurus takmir masjid yang secara stuktural ada di bawah koordinasi Pimpinan Ranting Muhammadiyah (PRM) Desa Gilangharjo. Tahapan ini ditempuh karena secara sistem organisasi PRM Desa Gilangharjo memiliki tugas untuk mengoordinasikan kegiatan-kegiatan di seluruh masjid yang ada di wilayah Desa 
Gilangharjo, mulai dari pengeloaan unit TPA, kegiatan kajian, kegiatan pemberdayaan masyarakat, pengelolaan keungan, sarana-prasarana, dan kebersihan.

\section{Pelatihan Manajemen Kegiatan Masjid}

Pada tahapan ini, diselenggarakan pelatihan manajemen pengelolaan kegiatan masjid yang meliputi manajemen pengeloaan unit TPA, kegiatan kajian, kegiatan pemberdayaan masyarakat, pengelolaan dana infak dan shadaqah, sarana-prasarana, dan kebersihan yang merupakan kegiatan mendasar yang harus terlaksana di masjid agar masjid dapat memberikan nilai dan fungsi bagi masyarakat melalui berbagai kegiatan yang dapat diselenggarakan.

Salah satu kegiatan yang mendapat apresiasi yang sangat baik dari masyarakat Daleman adalah pelatihan metode pembelajaran dan manajemen pengelolaan unit TPA. Acara ini tidak hanya diikuti oleh para pengajar dari masing-masing unit TPA yang sudah dibentuk, tetapi juga diikuti oleh sebagian besar takmir masjid. Tujuan kegiatan ini adalah untuk memberikan pelatihan pembelajaran dan standarisasi manajemen pengelolaan unit TPA sebagaimana standar nasional yang telah dirancang oleh Yayasan Team Tadarus AMM Yogyakarta. Tahapan ini juga dimaksudkan untuk memberi wawasan kepada seluruh ustaz dan ustazah di masing-masing unit TPA bahwa pengelolaan unit TPA dengan standar manajemen Yayasan Team Tadarus AMM Yogyakarta akan dapat menyemarakkan kegiatan masjid yang berada di lingkungan Dusun Daleman. Dalam rangkaian pada tahapan ini juga diselenggarakan koordinasi dengan pemerintah Desa Gilangharjo agar dapat memberikan perhatian khusus untuk keberlangsungan kegiatan-kegiatan masjid yang ada, baik berupa pendanaan maupun kebijakan (Abu Muhammad Iqbal, 2015: 96).

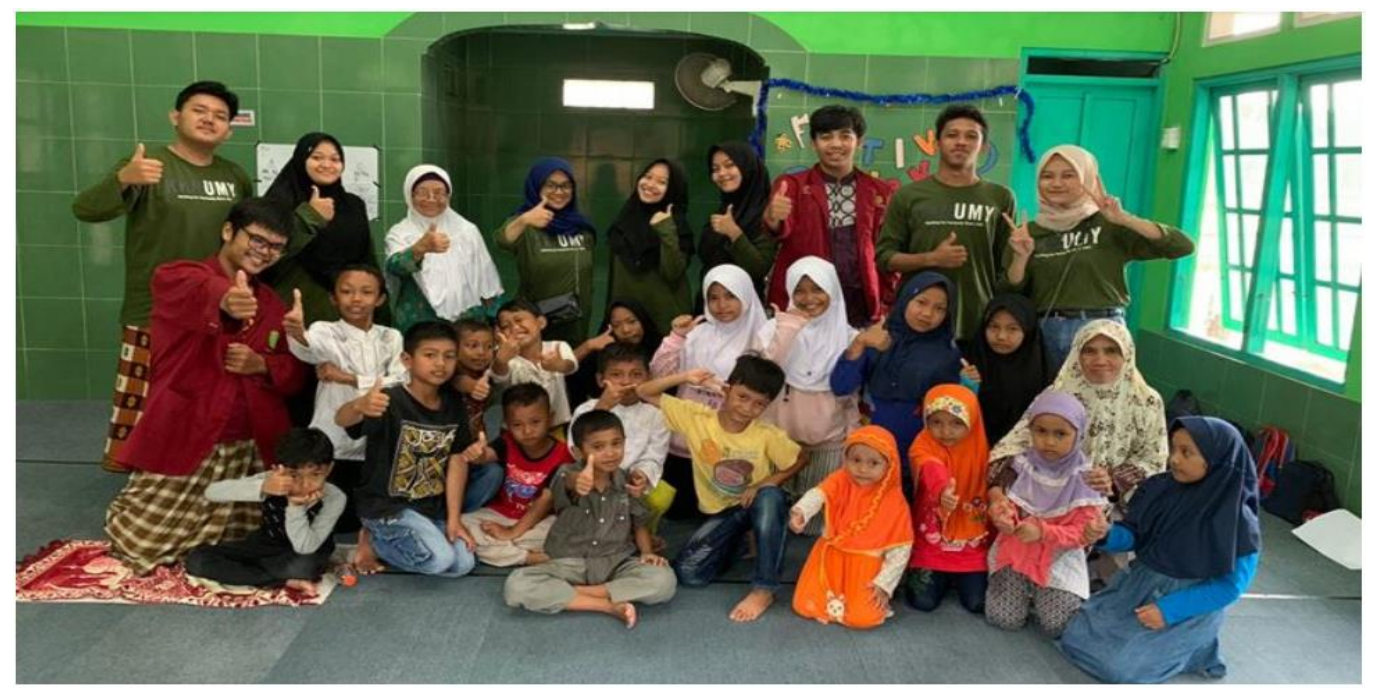

Gambar 3. Pelatihan pembelajaran dan manajemen pengelolaan unit TPA

\section{Pengadaan Fasilitas Masjid}

Rangkaian terakhir dari keseluruhan tahapan pengabdian masyarakat di Dusun Daleman ini adalah melengkapi fasilitas sekunder masjid, baik sarana maupun prasarana yang dibutuhkan untuk memberikan mutu pelayanan dan kenyamanan bagi para jamaah dalam melakukan ibadah dan berbagai kegiatan keagamaan dan kemasyarakatan. Tahapan ini menjadi penting agar program kerja masjid dapat berjalan sesuai dengan prosedur 
pengelolaan masjid. Tanpa adanya fasilitas yang memadai, tentu hasil yang diharapkan akan sangat sulit dicapai.

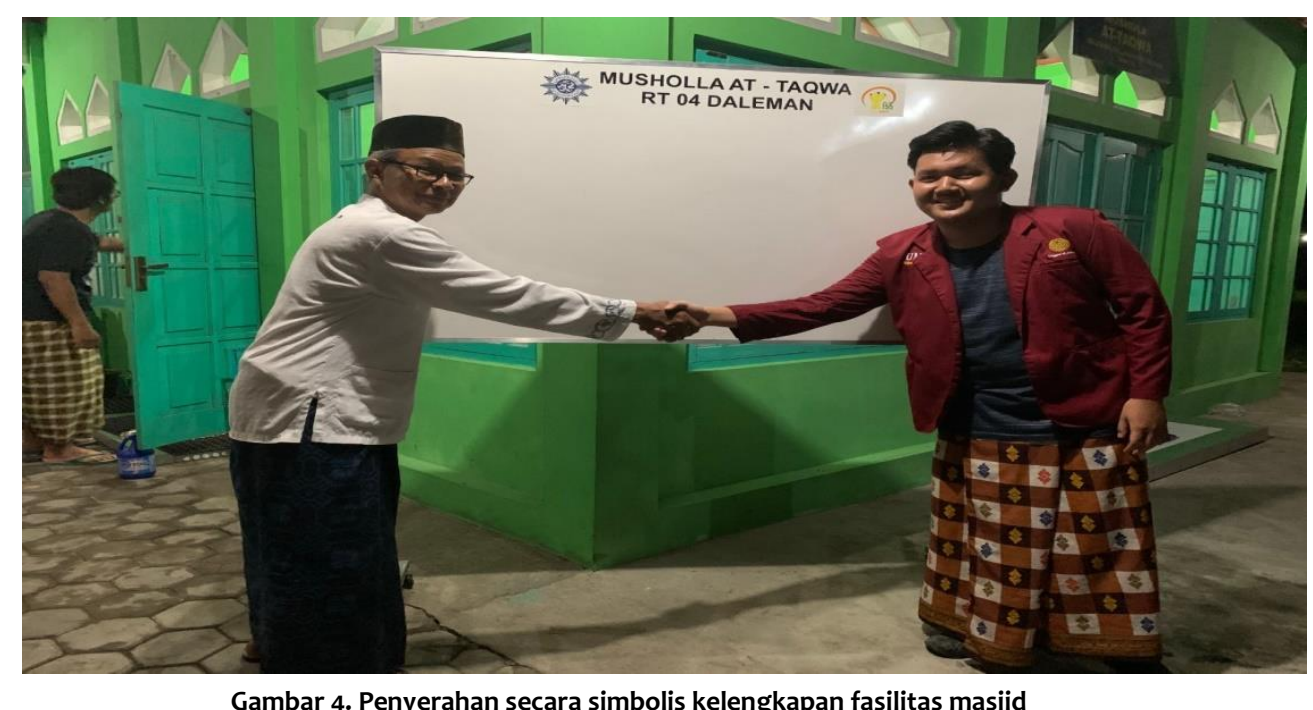

Adanya fasilitas yang memadai diharapkan program kerja masjid yang telah dirancang dapat direalisasikan sehingga dapat memberikan mutu pelayanan dan kenyamanan dalam berbagai bentuk kegiatan, baik berupa kegiatan kajian, sosial kemasyarakatan, peningkatan perekonomian umat, maupun menjadi ruang diskusi untuk mencari solusi permasalahan umat terkini bagi umat Islam di wilayah Dusun Daleman. Dengan demikian, masjid diharapkan dapat memberikan dampak positif dan membangun bagi kehidupan masyarakat pada berbagai lini kehidupan.

\section{Simpulan}

Kegiatan pengabdian kepada masyarakat di Dusun Daleman ini sudah selesai dengan terlaksananya berbagai kegiatan berupa pendampingan, di antaranya terbentuknya pengurus takmir masjid dan tersusunnya program kerja masjid dengan menerapkan iptek berupa manajemen pengelolaan masjid beserta kegiatannya. Dengan adanya kegiatan ini, diharapkan masing-masing masjid dapat menjadi rule model dan dapat terus berkembang hingga dapat memberikan kemanfaatan bagi kesejahteraan, kedamaian, dan kemajuan seluruh warga Dusun Daleman.

\section{Ucapan Terima Kasih}

1. LP3M Universitas Muhammadiyah Yogyakarta atas kontrak penugasan pengabdian kepada masyarakat tahun 2019/2020.

2. Kepala Dukuh Daleman, Ketua RT 04 Daleman, tokoh agama, tokoh masyarakat, dan seluruh warga Dusun Daleman, Gilangharjo, Pandak, Bantul, DI. Yogyakarta.

\section{Daftar Pustaka}

Humam, As'ad. 2001. Pedoman Pengelolaan, Pembinaan, dan Pengembangan Membaca, Menulis, dan Memahami Al-Quran (M3A). Yogyakarta: Balitbang LPTQ. 
Iqbal, Abu Muhammad. 2015. Pemikiran Pendidikan Islam. Yogyakarta: Pustaka Pelajar.

LPPI. 2017. Panduan Pembudayaan Tadarus Al-Qur'an. Yogyakarta: LPPI.

Samad, Duski. 2008. Manajemen Masjid Kota Padang. Padang: Dewan Masjid Indonesia.

Sophyia, Ida Vera dan Saiful Mujib. 2014. Dalam Jurnal Elementary Vol. 2 No. 2. Edisi JuliDesember. 